\title{
Anne Sütü Mikrobiyotası
}

\author{
Human Milk Microbiota
}

\author{
Meltem Dinleyici
}

\author{
Eskişehir Osmangazi Üniversitesi Tıp Fakültesi, Çocuk Sağlığı ve Hastalıkları Anabilim Dalı, \\ Sosyal Pediatri Bilim Dalı, Eskişehir, Türkiye
}

\begin{abstract}
Özet: Anne sütü ile beslenme, yaşamın erken döneminde mikrobiyota kompozisyonunu etkileyen önemli bir faktördür. Emzirmenin, bebeklerde mikrobiyota kompozisyonu üzerindeki etkisi 100 yıl önce tanımlanmıștır ve anne sütü oligosakkaritlerinin bağırsak mikrobiyota kompozisyonu üzerine etkisinin olduğu, özellikle bifidobakterileri arttırdığı gösterilmişstir. Anne sütü ile yapılan yeni nesil dizileme çalışmaları sonucunda, anne sütünün kendine özgü mikrobiyota içeriğine sahip olduğu gösterilmiștir. Anne sütü mikrobiyota içeriği ile ilgili daha önceden yapılan çalışmalarda en sık saptanan bakteriler, Streptococcus, Staphylococcus, Lactobacillus, Bifidobacterium, Enterococcus ve Propionibacterium olarak saptanmıştır. Bu bakterilere ek olarak, kısa zincirli yağ asitleri üretebilen Veillonella, Propionibacterium ve Faecalibacterium'un da anne sütünde mevcut olduğu gösterilmiștir. Anne sütü mikrobiyota içeriğinin doğum şekli ve gebelik haftasına göre değiştiği gösterilmiştir. Elektif sezaryen ile normal spontan doğum arasında anne sütü bakteriyel içeriği arasında fark olduğu gösterilmiştir. Doğum şekli ve gebelik haftanın ek olarak, annede obezite varlığı, annenin hamilelik sırasındaki psikolojik durumu ve intrapartum antibiyotik kullanımı da anne sütü bakteriyel mikrobiyotasını değiştirebilmektedir. Anne sütü mikrobiyota bileşiminin (bakteriyom, virom, mikobiyom) sezaryen doğum, prematürite, gestasyon haftasına göre düşük ya da yüksek doğum ağırlığı olmasına bağlı ya da geçiş/matür anne sütü arasında farklar olduğu gösterilmişti. Ek olarak, anne sütünün el ile ya da pompa ile sağılması durumunda da mikrobiyota içeriğinde değişiklik olduğu gösterilmiștir. Anne sütü mikrobiyotasının kaynağı halen net olarak bilinmemektedir. Anne sütü mikrobiyotası için potansiyel olarak tanımlanan kaynak, annenin bağırsağı ile meme dokusu arasındaki yol, anne cildinden süte transfer ve/ veya bebeğin ağız mikrobiyotasıdır. Kaynak ne olursa olsun, anne sütü içerisindeki mikrobiyota kompozisyonun, emzirme ile bebeğe aktarıldığı ve bebeğin bağırsak mikrobiyotasının gelișmesinde etkili olduğu gösterilmiștir. TEDDY çalışmasının sonuçları, yaşamın ilk 1000 gününde mikrobiyota gelişimi için en önemli faktörün emzirme olduğunu göstermiştir. Prebiyotikler de dahil olmak üzere anne sütü oligosakkarit içeriği de, anne sütü ve bebeğin bağırsak mikrobiyotasını etkileyebilmektedir. Anne sütü ile beslenen bebeklerde doğumdan kısa bir süre sonra, bağırsak mikrobiyota içeriğinde Bifidobakterilerin baskın tür olduğu gösterilmiştir. Anne sütünün bu yararlı etkileri için, annenin mikrobiyota kompozisyonun da sağlıklı olması gerekmektedir. Anne sütünün bebeğin bağırsak mikrobiyotası ve dolayısıyla bağışıklık sistemi üzerinde etkileri olduğu ve enfeksiyon ve hastalıkları ve enfeksiyon ile ilişikisi olmayan hastalıklardan korunma ile sonuçlandığı düşünülmektedir. Emzirme-mikrobiyom ve bağışıklık ontogenisi arasındaki etkileşimleri değerlendiren çalışmalar ile anne sütü mikrobiyotasının etkilerinin anlaşılmasına yardımcı olacaktır.
\end{abstract}

Anahtar Kelimeler: anne sütü, emzirme, mikrobiyota, mikrobiyom

\begin{abstract}
Breastfeeding is an important factor affecting early life microbiota composition. The effect of breastfeeding on the microbial composition of infants has been described 100 years ago and it has been shown that human milk oligosaccharides enhances the intestinal microbial composition, especially Bifidobacteria. As a result of recent new generation sequencing studies on human milk, it has been shown that human milk has microbiota content of its own. Previous studies on human milk microbiota composition, Streptococcus, Staphylococcus, Lactobacillus, Bifidobacterium, Enterococcus, and Propionibacterium are most abundant taxa. In addition, Veillonella, Propionibacterium, and Faecalibacterium, which can produce short chain fatty acids, have also been shown to be present in human milk. It was shown that the human milk microbiota content varies according to delivery mode and gestational age. There is a difference for bacterial composition of human milk between elective cesarean section and normal spontaneous birth. In addition to delivery mode and gestational age, maternal obesity, psychological status of mothers during pregnancy, and intrapartum antibiotics use may also alter the composition of human milk bacterial microbiota. We observed some changes that the human milk microbiota composition (bacteriome, virome, mycobiome) varies in caesarean delivery, premature, small for gestational age and large for gestational age groups, comparing the normal spontaneous delivery, as well as differences between transient and mature human milk. In addition, it has been shown that there is a change in microbiota content in case of hand-expression and pump expression of human milk. The source of the human milk microbiota is still unknown. Potential described source for human milk microbiota are the entero-mammary route of the mother, transfer from the mother's skin, and/or infant's oral microbiota. Regardless of the source of human milk microbiota, it has been clearly shown that human milk transferred to the infant's gut and breastfeeding is one of the determinants of the infant's intestinal microbiota. The results of the TEDDY study showed that the most important factor for microbiota composition was breastfeeding in the first 1000 days. Human milk oligosaccharides content including prebiotics, might affect the human milk microbiota and infant's intestinal microbiota. Bifidobacteria were found to be predominant strain in the intestinal microbiota content of infants fed with breast milk, in a short period after birth. The microbiota composition of human milk content is thought to play a significant role in the development of the infant's immune system. It is thought that human milk has effects on the intestinal microbiota of the infant and therefore on the immune system, resulting with the protection from infectious and non-communicable diseases. Further studies will help to understand the interactions between breastfeeding-microbiome and immune ontogeny.
\end{abstract}

Keywords: human milk, breastfeeding, microbiota, microbiome

ORCID ID of the author: M.D. 0000-0002-8353-6796

Received 03.02 .2020

Accepted 03.02.2020

Online published 23.03 .2020

Correspondence : Meltem DINLEYİCi - Eskişehir Osmangazi Üniversitesi Tıp Fakültesi, Çocuk Sağlığı ve Hastalıkları Anabilim Dalı, Sosyal Pediatri Bilim Dalı, Eskişehir, Türkiye e-mail: meltemayata@ hotmail.com 


\section{Giriş}

Mikrobiyota, insan vücudunda farklı anatomik bölgelerde birlikte yaşayan mikroorganizmaların (bakteri, virüs, arkea ve mantarlar dahil olmak) tamamina verilen isimdir. Mikrobiyom ise mikrobiyota kompozisyonunda yer alan tüm bu mikroorganizmaların genetik yüklerinin de dahil olduğu sistemdir (1). Mikrobiyota analizleri için kullanılan yeni nesil dizileme yöntemleri ile tanımlanması sonrasında geçmişte steril olduğu düşünülen, amniyon sıvısı ve anne sütü gibi birçok vücut sıvısında başta bakteriler olmak üzere mikrobiyota elemanları saptanmıştır (2-3). İlk 1000 gün gebeliğin ilk gününden, bebeğin üçüncü yaş gününe kadar olan dönem olup, bu dönem üzere etkili faktörlerin, bebeklik dönemi ve daha sonrasında erişkinlik dönemi de mikrobiyota kompozisyonu üzerine etkileri birçok hastalık tablosu ile ilişkili olabildiği düşünülmektedir (4). İlk 1000 gün üzerine etkili faktörlerin değerlendirildiği en geniş çalışma TEDDY çalışmasıdır (5). Amerika Birleşik Devletleri, Almanya ve Finlandiya'da 1000 'e yakın bebeğin, ilk 3 yıl mikrobiyota kompozisyonu üzerine etkili faktörlerin değerlendirildiği çalışmada annenin gebelik öncesi vücut kitle indeksi, gebelik dönemindeki sağlık durumu, kullandığ 1 ilaçlar, doğum şekli, emzirme, bebeğin ortak yaşam alanı ile ilişkili faktörlerin ve bebeğin diğer beslenme ilişkili faktörlerinin mikrobiyota kompozisyonunda geçici ya da kalıcı değişikliklere neden olduğu gösterilmiştir. TEDDY çalışmasında yaşamın ilk 3 yılında bebeğin intestinal mikrobiyotası üzerine etkili faktörler arasında en belirleyici etkiyi anne sütü ile beslenmenin oluşturduğu gösterilmiştir. Yalnız anne sütü ile beslenen bebeklerin bağırsaklarında \%80'e yakın oranda bifidobakterilerin baskın olduğu bir mikrobiyota olduğu gösterilmiştir (5).

Anne sütü ile beslenen bebeklerin mikrobiyota kompozisyonu üzerine etkisi 100 y1l öncesinde tanımlanmış olup, anne sütü içerisindeki oligosakkaritlerin (bifidus faktör) intestinal mikrobiyota Bifidobakteri kompozisyonunu arttırdığ1 gösterilmiştir (4). Bununla birlikte anne sütünün 2003 y1lına kadar steril olduğu düşünülmekte idi. 2003 yılında Martin ve arkadaşlarının (6) yaptıkları çalışmada, anne sütü içeriğinde endojen kaynaklı laktik asit bakterilerinin bulunduğunu ve anne sütü laktik asit bakterilerinin bebeğin intestinal mikrobiyotasının en önemli kaynağı olduğunu göstermişlerdir. $\mathrm{Bu}$ çalışmayı takip eden dönemde anne sütünün mikrobiyota içeriğinin detaylı değerlendirmeleri yapılmış, bu içeriğin de doğum şekli ve gestasyon haftasına göre farklılıkları olduğu gösterilmiştir (3, 7-9). Anne sütü içeriğinde baskın bulunan türler Streptococcus, Staphylococcus, Lactobacillus, Bifidobacterium, Enterococcus, ve Propionibacterium olduğu gösterilmiştir (910). Anne sütü mikrobiyotasında bağırsak kaynaklı zorunlu anerob mikrooragnizmalar olan Blautia, Clostridium, Collinsella, ve Veillonella türlerinin yanında kısa zincirli yă asiti üretebilen Coprococcus, Faecalibacterium ve Roseburia türlerinin de anne sütü içeriğinde bulunduğu gösterilmiştir (9-10). Anne sütü mikrobiyota içeriği ile ilgili yapılan çalışmalarda farklı sonuçlar elde edilmiştir ve bu değişiklikler coğrafi bölgeler, etnik farkl11ıklar, anneye ve bebeğe ait faktörler ile açıklanmaya çalışılmıştır (3, 914). Anne sütü mikrobiyotası ile ilgili yapılan bir meta-analiz çalışmasında Staphylococcus ve Streptococcus türlerinin tüm çalışmalarda baskın mikroorganizmalar olarak yer aldığ Pseudomonas ve Lactobacillus suşlarının birçok çalışmada ortak görülen suşlar arasında yer aldığı gösterilmiştir (15).

Anne sütü mikrobiyotası üzerine etkili faktörler üzerine en geniş ve uzun süreli takip çalışması CHILD çalışmasıdır (16-17). Kanada'da Azad ve ark. (16) tarafindan yürütülen çalışmada, 393 emziren anne ve bebeği uzun süreli olarak takip edilmiş, anne ile ilişkili faktörler (VKİ, yaş, etnik farklılık, diyet), emzirme ile ilişkili faktörler (tek başına anne sütü, anne sütü toplama zamanı ve şekli), doğum şekli, antibiyotik kullanımı, evde kardeş varlığı, bebeğin cinsiyeti ve doğum ağırlığı değerlendirilmiştir. CHILD çalışmasında, anne sütü mikrobiyotasında en etkili faktörlerin annenin vücut kitle indeksi, doğum şekli ve tek başına anne sütü ile 
beslenmenin belirleyici olduğu gösterilmiştir (16-17).

Doğum şeklinin bebeğin intestinal mikrobiyota kompozisyonu yanında, anne sütü mikrobiyotası üzerine de etkilerinin olduğu gösterilmiştir $(4,7)$. Normal vajinal yol ile doğan bebeklerde, anne sütü mikrobiyal çeșitliliğinin daha fazla olduğu, Bifidobacterium ve Lactobacillus baskın bir mikrobiyota olduğu gösterilmiştir. Sezaryen ile doğumun anne sütü mikrobiyotası üzerine etkileri olmakla birlikte, elektif sezaryen ile acil sezaryen arasında da farklılıklar olduğu, acil sezaryen olan olgularda, fizyolojik süreçlerin başlaması, stres ve hormonların etkisi ile normal doğuma göre daha az fark gösteren bir mikrobiyota kompozisyonu olduğu gösterilmiştir (4). Anne sütü mikrobiyotası üzerine etkili bir diğer önemli faktör intrapartum antibiyotik kullanımı olup, normal vajinal yol ya da sezaryen doğum olsa da intrapartum antibiyotik kullanımının her iki koşulda da anne sütü mikrobiyotasını olumsuz etkilediği gösterilmiştir (19). Cabrera-Rubio ve ark. (18) anne sütü mikrobiyota içeriğini değerlendirdikleri çalışmalarında, obez annelerin anne sütü mikrobiyota içeriğginin, daha az çeşitlilik gösterdiğini tanımlamışlardır.2019 yılında yayınlanan CHILD çalışmasının bir diğer analizinde, anne sütü elle sağılması ve pompa ile sağılmasının da mikrobiyota kompozisyonu üzerine etkilerinin olduğu, elle sağmada Bifidobacterium suşlarının daha baskın olduğu gösterilmiştir (17). 2017 yılında Kloop ve ark. (20) pompa ile sağılmış anne sütü ile beslenen bebeklerde tek başına anne sütü ile beslenen bebeklere göre astım sıklığının daha fazla olduğunu göstermişlerdir, ancak bu durumun pompa ile sağılan anne sütünün değişen mikrobiyotası ile ilişkisi henüz gösterilmemiştir. Anne sütü mikrobiyom içeriğinin kaynağı ile farklı sonuçlar olmakla birlikte henüz net kaynağ 1 ya da tek bir kaynağ1 olup olmadığı tanımlanamamıştır. Potansiyel etkili 3 mekanizma tanımlanmıștır $(14,21)$.

1. Geri akış: Bebeğin ağzı ya da annenin meme cildinden emzirme sırasında geri akış
2. Bağırsak Meme Aksı: Non-patojenik bakterilerin anne bağırsağından meme dahil diğer dokulara taşınması

3. Meme Dokusu Bakteriyomu: Meme dokusunun meme biyopsilerinde gösterilmiş kendi mikrobiyota içeriği

Boix-Amoros ve ark. (21) anne sütü mikrobiyotasının kaynağı olarak son veriler 1şığında en etkili faktörlerin anne cildi ve bebeğin ağı mikrobiyotasını tanımlamışlardır. Ancak 2019 yılında yayınlanan son çalışmada annelerin doğumdan önceki üç günde prekolostrum örnekleri toplanmıș ve bu örneklerde mikrobiyota elemanlarının saptanması bebeğin oral mikrobiyotasının anne sütünün (en azından erken dönemde) belirleyicisi olmadığını göstermiştir (22). Türkiye'de anne sütü mikrobiyotası ile ilgili yürüttügümüz çalışmada, annelerin mikrobiyota kompozisyonu bakteri, virüs, mantar içeriği ile değerlendirilmesi planladık (23). Çalışmada Haziran 2017- Mayıs 2018 tarihleri arasında Eskişehir Osmangazi Üniversitesi ve İstanbul Medeniyet Üniversitesi'nde, 44 anneden, 88 anne sütü örneği alındı. Çalışma grupları normal vajinal doğum-term, sezaryen-term, prematüre, SGA, LGA olarak belirlendi. Geçiş sütü (7-15. gün) ve matür süt (45-90 gün) bebeklerin normal kontrol muayeneleri sirasinda annelerden toplandı. Tüm annelerden hastane ortamında, sabah erken, rutin emzirme öncesinde ön süt örneği alındı. Mikrobiyom analizleri tüm gen dizileme yöntemi ile yapıldı. Çalışmamızda anne sütü bakteriyom, virome ve mikobiyom kompozisyonun, doğum şekli, doğum ağırlığı, prematürite ile farklılıklar gösterdiği, bunun yanında geçiş sütü ve matür sütü arasında da farkl1l1klar olduğu gösterildi. Anne sütü mikobiyota (mantar) içeriğini gösteren az sayıda çalışmada anne sütü mikobiyota içeriğinin doğum şeklinden etkilendiği gösterilmiştir (24-25). 2019 yılında yapılan çalışmada İspanya, Finlandiya, Güney Afrika ve Çin'den alınan anne sütü örneklerinin mikobiyom içeriklerinin farklı olduğu, coğrafi bölgelerin ve etnisitenin mikobiyotay etkileyebildiği gösterilmiştir (25). Anne sütü örneklerinde bizim çalışmamızda da benzer şekilde Malessezia, Saccharomyces, 
Aspergillus ve Penicilillium en s1k gösterilen türler olmuştur. Türkiye'de yapılan çalışmamızda, mantarlar anne sütünün bakterilere göre daha küçük bir bölümünü oluşturmakla birlikte, anne sütü mikobiyota içeriğinin sezaryen doğum, prematürite, SGA ve LGA doğan bebeklerde, normal vajinal doğuma göre farklılıkları olduğu gösterilmiştir. Çalışmamızda aynı zamanda geçiş sütü ve matür süt arasında da mikrobiyota içeriği yönünden farkl11ıklar olduğu gösterilmiştir (23).

Anne sütü virüs içeriği ile ilgili çalışmalar kısıtlı olup, suş düzeyinde değerlendiren çalışma yoktur. $\mathrm{Bu}$ konuda yapılan tek çalışmada, ABD'de Meksika kökenli 10 annebebek (yedisi normal doğum) değerlendirilmiş ve geçiş sütünde ve bebeğin gaitasında virom analizi yapılmıştır (26). Bu çalışmada bebeğin bağırsağı ile anne sütü virom içeriğinin benzer olduğu ve bebeğe virüslerin emzirme ile geçtiği gösterilmiştir. $\mathrm{Bu}$ çalışmada hem bebeğin gaitasında $(\% 95.5 \pm 3.2)$ hem de anne sütünde $(\% 95.2 \pm 2.8)$ en sik saptanan virüsler bakteriofaj grubu olup, ökaryotik virüsler küçük bir bölümü oluşturmuştur. Bizim çalışmamızda da bakteriyofajlar anne sütü viromunun önemli bölümünü oluşturmaktadır ve doğum şekli, doğum ağrıllğı ve prematürite anne sütü viromunu etkilemektedir (27). Anne sütü viromu içerisinde bu değişiklikler patolojiden çok bebeğin ihtiyaçları doğrultusunda bir adaptasyon olabilir. Bakteriyofajlar, anne sütü viromunun en büyük kısmı olup, anne sütünün antibiyotik özelliği olup, bebekte enfeksiyonların

\section{KAYNAKLAR}

1. Filyk HA, Osborne LC. The Multibiome: The intestinal ecosystem's influence on immune homeostasis, health, and disease. EBio- Medicine 2016; 13: 46-54.

2. Urushiyama D, Suda W, Ohnishi E, Araki R, Kiyoshima C, Kurakazu M, Sanui A, Yotsumoto F, Murata M, Nabeshima K, Yasunaga S, Saito S, Nomiyama M, Hattori M, Miyamoto S, Hata K. Microbiome profile of the amniotic fluid as a predictive biomarker of perinatal outcome. $\mathrm{Sci}$ Rep. 2017; 7: 12171.

3. Fitzstevens JL, Smith KC, Hagadorn JI, Caimano MJ, Matson AP, Brownell EA. Systematic review of the human milk microbiota. Nutr Clin Pract. 2017; 32: 354-64. gelişmesinde ve antibiyotik direncinin azalmasında rol oynuyor olabilir, bu durumun daha geniş çalışmalar ile değerlendirilmesi gerekmektedir.

Anne sütü mikrobiyota içeriğinin ve dolayısı ile bebeğin mikrobiyotası için önemli bir belirleyici, anne sütünün prebiyotik (oligosakkarit) içeriğidir (28). Anne sütü ile beslenen bebeklerin intestinal mikrobiyota içeriğinde kı süre içerisinde Bifidobakteriler'in hakim olduğu gösterilmiştir. Yaşamın ilk altı ayında yalnız anne sütü alan bebeklerde, erişkinden çok farklı ama bebeğin ihtiyaçlarına yönelik olduğu, \%75 Bifidobacterium egemen, bazen $\% 100$ Bifidobacterium infantis seklinde olduğu gösterilmiştir. Ancak anne sütünün bu yararlı etkilerinin olabilmesi için annenin mikrobiyotasının da sağlıklı olması gereklidir $(4,29)$

Anne sütü ile beslenen bebeklerin başta üst ve alt solunumu yolu enfeksiyonu, akut ishal ve alerjik hastalıklar olmak üzere birçok hastalıktan korunduğunu göstermiş olup, son yıllarda yapılan çalışmalarda anne sütü ile beslenen çocukların obezite, diyabet, lösemi gibi kronik ve ciddi hastalıklardan da korunabildiği gösterilmiștir. Anne sütünün başta immün aracılıklı hastalıklar olmak üzere hastalıklardan koruyucu etkisinde, bebeğin intestinal mikrobiyotası üzerine ve dolayısı ile immün sistem üzerine etkileri ile olduğu düşünülmektedir ancak direkt anne sütü beslenmesi-mikrobiyom ve immün ontogeni ilişkisinin gösterilebilmesi için daha geniş çalışmalara ihtiyaç duyulmaktadır $(4,7,15)$.

4. Dinleyici M, Kılıç Ö, Dinleyici EÇ. İlk 1000 Gün: Fetal Hayattan Çocukluğa Mikrobiyota. Karakuş R, editör. Mikrobiyota İmmünolojisi. Ankara: Türkiye Klinikleri; 2018. p.13-8.

5. Stewart CJ, Ajami NJ, O'Brien JL, Hutchinson DS, Smith DP, Wong MC, Ross MC, Lloyd RE, Doddapaneni H, Metcalf GA, Muzny D, Gibbs RA, Vatanen $\mathrm{T}$, Huttenhower C, Xavier RJ, Rewers M, Hagopian W, Toppari J, Ziegler AG, She JX, Akolkar B, Lernmark A, Hyoty H, Vehik $\mathrm{K}$, Krischer JP, Petrosino JF. Temporal development of the gut microbiome in early childhood from the TEDDY study. Nature. 2018; 562: 583-8. 
6. Martín R, Langa S, Reviriego C, Jimínez E, Marín ML, Xaus J, Fernández L, Rodríguez JM. Human milk is a source of lactic acid bacteria for the infant gut. J Pediatr. 2003; 143 754-8.

7. Amenyogbe N, Kollmann TR, Ben-Othman R. Early-Life Host-Microbiome Interphase: The Key Frontier for Immune Development. Front Pediatr 2017; 5: 111.

8. Urbaniak C, Angelini M, Gloor GB, Reid G. Human milk microbiota profiles in relation to birthing method, gestation and infant gender. Microbiome 2016; 4: 1.

9. Jost T, Lacroix C, Braegger C, Chassard C. Impact of human milk bacteria and oligosaccharides on neonatal gut microbiota establishment and gut health. Nutr Rev 2015; 73: 426-37.

10. McGuire MK, McGuire MA. Got bacteria? The astounding, yet not-so-surprising, microbiome of human milk. Curr Opin Biotechnol. 2017;44:63-8.

11. Hunt KM, Foster JA, Forney LJ, Schütte UM, Beck DL, Abdo Z, Fox LK, Williams JE, McGuire MK, McGuire MA et al. Characterization of the diversity and temporal stability of bacterial communities in human milk. PLoS One. 2011; 6: e21313.

12. Murphy K, Curley D, O'Callaghan TF, O'Shea CA, Dempsey EM, O'Toole PW, Ross RP, Ryan CA, Stanton C. The composition of human milk and infant faecal microbiota over the first three months of life: A Pilot Study. Sci Rep. 2017; 7: 40597.

13. Jiménez E, de Andrés J, Manrique M, ParejaTobes P, Tobes R, Martínez-Blanch JF, Codoñer FM, Ramón D, Fernández L, Rodríguez JM. Metagenomic Analysis of Milk of Healthy and Mastitis-Suffering Women. J Hum Lact. 2015; 31: 406-15.

14. Ruiz L, García-Carral C, Rodriguez JM. Unfolding the Human Milk Microbiome Landscape in the Omics Era. Front Microbiol. 2019; 10: 1378.

15. Ojo-Okunola A, Nicol M, du Toit E. Human Breast Milk Bacteriome in Health and Disease. Nutrients. 2018; 10. pii: E1643.

16. Azad MB, Konya T, Persaud RR, Guttman DS, Chari RS, Field CJ, Sears MR, Mandhane PJ, Turvey SE, Subbarao P, Becker AB, Scott JA, Kozyrskyj AL; CHILD Study Investigators. Impact of maternal intrapartum antibiotics, method of birth and breastfeeding on gut microbiota during the first year of life: a prospective cohort study. BJOG. 2016; 123: 983 93.

17. Moossavi S, Sepehri S, Robertson B, Bode L, Goruk S, Field CJ, Lix LM, de Souza RJ, Becker $\mathrm{AB}$, Mandhane PJ, Turvey SE, Subbarao P, Moraes TJ, Lefebvre DL, Sears MR, Khafipour E, Azad MB. Composition and Variation of the Human Milk Microbiota Are Influenced by Maternal and Early-Life Factors. Cell Host Microbe. 2019; 25: 324-35.

18. Cabrera-Rubio R, Kunz C, Rudloff S, GarcíaMantrana I, Crehuá-Gaudiza E, Martínez-Costa C, Collado MC. Association of Maternal Secretor Status and Human Milk Oligosaccharides With Milk Microbiota: An Observational Pilot Study. J Pediatr Gastroenterol Nutr. 2019; 68: 256-63.
19. Hermansson H, Kumar H, Collado MC, Salminen S, Isolauri E, Rautava S. Breast Milk Microbiota Is Shaped by Mode of Delivery and Intrapartum Antibiotic Exposure. Front Nutr. 2019; 6: 4.

20. Klopp A, Vehling L, Becker AB, Subbarao P, Mandhane PJ, Turvey SE, Lefebvre DL, Sears MR; CHILD Study Investigators, Azad MB. Modes of Infant Feeding and the Risk of Childhood Asthma: A Prospective Birth Cohort Study. J Pediatr. 2017; 190: 192-9.

21. Boix-Amorós A, Collado MC, Van't Land B, Calvert A, Le Doare K, Garssen J, Hanna H, Khaleva E, Peroni DG, Geddes DT, Kozyrskyj AL, Warner JO, Munblit D. Reviewing the evidence on breast milk composition and immunological outcomes. Nutr Rev. 2019 May 21. pii: nuz019.

22. Ruiz L, Bacigalupe R, García-Carral C, BoixAmoros A, Argüello H, Silva CB, de Los Angeles Checa M, Mira A, Rodríguez JM. Microbiota of human precolostrum and its potential role as a source of bacteria to the infant mouth. Sci Rep. 2019; 9: 8435 .

23. Dinleyici M, Pérez-Brocal V, Arslanoglu S, Aydemir O, Ozumut SS, Tekin N, Vandenplas Y, Moya A, Dinleyici EC. Human milk mycobiota composition: relationship with gestational age, delivery mode, and birth weight. Benef Microbes. 2020;28:1-12.

24. Boix-Amorós A, Martinez-Costa C, Querol A, Collado MC, Mira A. Multiple Approaches Detect the Presence of Fungi in Human Breastmilk Samples from Healthy Mothers. Sci Rep. 2017; 7: 13016.

25. Boix-Amorós A, Puente-Sánchez F, du Toit E, Linderborg KM, Zhang Y, Yang B, Salminen S, Isolauri E, Tamames J, Mira A, Collado MC. Mycobiome Profiles in Breast Milk from Healthy Women Depend on Mode of Delivery, Geographic Location, and Interaction with Bacteria. Appl Environ Microbiol. 2019; 85. pii: e02994-18.

26. Pannaraj PS, Ly M, Cerini C, Saavedra M, Aldrovandi GM, Saboory AA, Johnson KM, Pride DT. Shared and Distinct Features of Human Milk and Infant Stool Viromes. Front Microbiol. 2018;9:1162.

27. Dinleyici M, Pérez-Brocal V, Arslanoglu S, Aydemir O, Ozumut SS, Tekin N, Vandenplas Y, Moya A, Dinleyici EC. Human milk virome analysis: changing pattern regarding to mode of delivery, birth weight and lactational status. 7 th International Conference on Nutiriton and Growth, 26-28 March 2020, London, United Kingdom.

28. Gomez-Gallego C, Garcia-Mantrana I, Salminen $\mathrm{S}$, Collado MC. The human milk microbiome and factors influencing its composition and activity. Semin Fetal Neonatal Med 2016; 21 : 400-5.

29. Underwood MA, German JB, Lebrilla CB, Mills DA. Bifidobacterium longum subspecies infantis: champion colonizer of the infant gut. Pediatr Res 2015;77:229-35. 